\title{
Consideration of demand rate in Overall Equipment Effectiveness (OEE) on equipment with constant process time
}

\author{
Perumal Puvanasvaran, Y.S. Teoh, C.C. Tay \\ University Technical Malaysia Melaka (Malaysia) \\ punesh@yahoo.com,ysteob1987@,hotmail.com
}

\section{Abstrad:}

Purpose The paper is primarily done on the purpose of introducing new concept in defining the Overall Equipment Effectiveness (OEE) with the consideration of both machine utilization and customer demand requested. Previous literature on limitation and difficulty of OEE implementation have investigated in order to track out the potential opportunities to be improved, since the OEE has been widely accepted by most of the industries regardless their manufacturing environment.

Design/methoddogy/approadr The design is rely primarily on literature review and computerized data. In details, the novel definition and method of processing the computerized data are all interpreted based on similar studies performed by others and supported by related journals in proving the validation of the output. Over the things, the computerized data are the product amount and total time elapsed on each production which is automatically recorded by the system at the manufacturing site.

Findings: The findings of this paper placed into two dimensions. The first is exposure and emphasis of limitation exists in current implementation of OEE, which showing that high utilization of the machine is encouraged regardless of the customer demand and is having conflict with the inventory handling cost. This is certainly obvious with overproduction issues especially during low customer demand period. The second is, the limitation in general 
implementation of $\mathrm{OEE}$ is the difficulty in obtaining the ideal cycle time, especially those equipments with constant process time. The section of this paper afterward comes out with the proposed solution in fixing this problem through the definition of performance ratio and then usage this definition in measuring the machine utilization from time to time. Before this, the time available for the production is calculated incorporating the availability of OEE, which is then used to get the Takt time.

Research limitations/implications: Future research should be conducted to examine the possibility and to verify the definition of such performance ratio including Takt time on those processes of which its operating time is possibly to be reduced, especially those are not constant and fixed. This piece of research is temporarily done on the process where its operating time is constant from time to time and there is no ideal cycle time possible.

Practical implications: The awareness of the overproduction should be emphasized and raised in the intention of pursuing higher OEE value. As the definition proposed, the process with constant cycle time could even be defined in different performance ratio from time to time regarding the customer demands and corresponding production rate. These two variables can be adjusted and balanced to increase the OEE value through optimization of average cycle time. Over this, optimization of average cycle time on equipment with constant operating time can be achieved through the optimization of loading number per each processing.

Originality/value The novelty of the paper comes from the inclusion of customer demand in obtaining OEE value of any particular equipment. Besides that, the equipment without ideal cycle time, which means those processes carried out in constant cycle time are possibly to be evaluated with performance ratio. As a consequence, the machine utilization and capacity used could be quantified and visualized using the performance ratio data of the OEE proposed.

Keyword: Overall Equipment Effectiveness (OEE), Takt time, average cycle time, performance ratio, availability

\section{Introduction}

It is called lean as it uses less, or the minimum, of everything required to produce a product or perform a service (Hayes \& Pisano, 1994). It is therefore the elimination of seven important wastes is important in Lean environment to ameliorate the effects of variability in supply, processing time or demand (Shah \& Ward, 2007). However, it is very difficult to find a concise definition which everyone agrees. Different authors define it distinctively (Wong, Wong \& Ali, 
2009). The same goes to the implementation of OEE, which is one of the lean tools. The ambiguity of the OEE implementation is especially outstanding during the classification of the element and acquisition of precise data during the computation of OEE. This could be seen from the evaluation of performance ratio in the equipment which carries out process with fixed cycle time. The difficulty faced in this situation including the acquisition and definition of the ideal cycle time since it's preset as per recipe or process parameter, constant from time to time and unchangeable. This could further contribute to deviation in evaluating the utilization and performance of a particular production cell (machine).

According to Williamson, there is no specific value for so-called "world-class OEE regardless of 85 percent OEE which has been cited frequently (2006). This means the action of maximizing and pursuing for high OEE value may not be justifiable. In that, optimum levels of OEE is largely dependent of the capability or capacity of the asset, the business demands, and whether it is a constraint in the process flow. The idea from the statement is that high level of production rate implied in high OEE (availability), if ignoring the low business demand, will contribute to expensive inventory handling cost. Besides that, the ideal cycle time is always difficult to be defined whereas the speed loss, minor stoppage, and idling are hardly to be differentiated from the waiting time. (Bamber, Castka, Sharp \& Motara, 2003; Kenis, 2006). Besides that, setup and adjustment time which increase accordingly with the product mix in manufacturing company will adversely affect the OEE value (Mileham, Culley, McIntosh, Gest \& Owen, 1997). In other words, mass manufacturing of several product mixes should be compromised due to high-OEE emphasis, of which is illogical from the perspective of business. Regarding to this, there is a need to improve the productivity of a manufacturing organization with respect to different market and product mixes (Hilmola, 2005), at the same time considering the customer demand in pursuing high OEE value and defining ideal cycle time particularly on machines with fixed and constant process cycle time.

The OEE value once being evaluated is just a displayed value and indication of current utilization of machine only. The story behind the value is seldom tracked out and the corresponding action in optimizing the machine utilization is not implicit. So, there is a need for internal flexibility within manufacturing system which will require changes of traditional organization methods to manage, measure, and mindset of management and employees on the role (Sweeney, 1990). Also, the integration of OEE with other lean tools is very poor and the leaner production system is hard to achieve without the integration of different lean tools. This is very crucial since production floor employees who are not well aligned with a philosophy will exhibit lower levels of desired attitudes and behaviors (Gagnon \& Michael, 2003).

In order to fix the issue stated above, the paper is structured to start with review of literature concerning the OEE contribution and its working mechanism so that the limitation and difficulty could be tracked out in detail. It's revealed that the traditional definition of OEE doesn't relate the utilization of machine with the customer demand. The performance ratio is not applicable 
on the machine with constant cycle time since the ideal time for this kind of equipment is fixed and couldn't be improved as per process requirement or recipe. Section three following of that is the methodology designed to conduct the project whereas section four is presenting the data and computation of the result. Explanation of data processed is made based on the literature review done and supported by the theories from previous studies. Lastly, Section five concludes the findings and suggests path for future research endeavours.

\section{Literature review}

This section contains all the related review of OEE which comprises of introduction, implementation method and the difficulty as well as limitations faced. The research on previous similar studies and journals had been done. The conclusion and concept from those studies are then gathered and summarized in this section to simplify the overall idea of the related topics so that it could be used as supportive materials of the findings and conclusion made.

\subsection{Overall Equipment Effectiveness (OEE)}

The overall equipment effectiveness (OEE) is a metric for evaluating the progress of Total Productive Maintenance (TPM), which is interpreted as the multiplication of availability, performance and quality. The improvement of OEE is via looking into the six big losses which are responsible for availability, performance ratio, as well as quality ratio of OEE and are classified under three main losses. According to Tajiri and Gotoh (1992) the relationship between OEE and losses depends on equipment availability, their performance rates and the quality of the product. Tajiri and Gotoh (1992) classified major losses into six groups. Breakdown losses, setup and adjustment losses are downtime losses used to determine a true value for the availability of a machine. The third and fourth losses including minor stoppage and reduced speed losses and are known as speed losses. They are used as a measure of performance rate of a given machine. Rework and yield losses are defined as quality losses to determine the quality rate for the equipment.

In details, the stated availability factor measures the total time that the system is not operating because of breakdowns, set-up, adjustment, and other stoppages (Jonsson \& Lesshammar, 1999). The equipment's total length of operation after any deduction of planned activities that may have disrupted production, for examples like scheduled and planned maintenance, official production breaks, process improvement initiatives or equipment tests, maintenance performed by the machine operator (e.g. equipment cleaning), operator training, etc, is considered as operating time in the computation of availability.

On the other hand, the second OEE element named performance rate measures the ratio of the actual operating speed of the equipment (e.g. the ideal speed minus speed losses, minor stoppages and idling) as compared to its ideal speed (Jonsson \& Lesshammar, 1999). The third element of OEE is quality (Q) indicating the proportion of defective production to the total 
production volume. An important characteristic that should be noted is that the quality concept, as defined by Nakajima (1988), only involves defects that occur in that designated stage of production, usually on a specific machine or production line and not elsewhere.

There is an element to be integrated with the three elements of OEE stated above named planning factor. It is a measure for the utilization of the installation in the theoretical production time or measure for the extent of not utilizing the installation. It can be quantified in as planning factor = Available production rate/ theoretical maximum production rate. The available production rate is the production amount or loading of which production is normally planned/ realized. The span of the available production time can vary for the planned as well as the realized value (Wauters \& Mathot, 2007).

The theoretical production rate is the maximum possible amount of a particular process available in the observed period and is a constant from time to time. The idea here is that the maximum capacity for a particular machine is 10,000 units per hour, for example, but the planner just plans for the available rate of 9,000 units per hour.

\subsection{Application of OEE}

Regardless of the generic definition and initial design intent of $O E E$, there are numerous applications of OEE applicable on the actual manufacturing site. Dal, Tugwell \& Greatbanks (2000) pointed out that, OEE measure can provide topical information for daily decision making by utilizing available performance data, such as preventive maintenance, material utilization, absenteeism, accidents, labor recovery, conformance to schedule, set-up and changeover data. On the other hand, Hansen (2001) described OEE as a powerful production and maintenance tool for increasing profit. Bamber et al. (2003) discussed OEE as a total measure of performance and concluded that cross-functional team working is essential for its success.

There is a necessity to find out the causes of these losses and start the improvements process. The idea is to make the equipment works as it should be working always and producing as much as it is supposed to produce, one cannot accept that it's producing less than anyone else having the same equipment and one should always seek for the best performance at all (Wireman,2004). In other words, the aims of TPM is to achieve the ideal performance and achieve the Zero loss which means no production scrap or defect, no breakdown, no accident, no waste in the process running or changeover (Nakajima, 1998).

Once the relationship between losses and OEE is clearly defined, it's obvious to know that OEE attempts to identify production losses and other indirect and "hidden" costs, which according to Ericsson (1997) are those that contribute with a large proportion of the total cost of production. In addition to that, one of the most famous interpretation and definition of OEE would be the view from Williamson (2006), said that; OEE is used in two formats, i.e. in data 
and in calculated OEE percentage. The data includes quantified loss reasons categorized as availability, availability, and quality ratio; whereas the calculated OEE percentage is the total measure acts as comparison metric used for a specific equipment or process over a period of time.

\subsection{Difficulty and limitation faced on OEE}

One of the important contributions of OEE is to consider equipment's hidden losses in term of equipment utilization. However, the OEE value will be affected by the product types and combination produced by a particular machine. The machine with various product-typed productions will normally have many changeovers and this will skew the availability of the machine. On top of that, human bias during the record of the data especially in defining the minor stoppage will cause the value of the date to be deviating from the actual value. The most important problem may exist is that the OEE value calculated is just a display and normally the possibility of demand achievement is not examined using OEE value.

Schmenner and Vollmann (1994) showed in an empirical study that most studied companies needed seriously to consider changing their performance measurement. They argued that most organizations were both using wrong measures and failing to use the right measures in correct ways. This is serious and it therefore seems important to identify the critical dimensions in a performance measurement system (what to measure) and the optimum characteristics of the measures (how to measure).

Unavailability or infeasibility of data to be collected in the form required for each formula is another difficulty of OEE implementation. For instance, often companies struggle to define an ideal cycle time, particularly in non-machinery and less well-automated manufacture (Bamber et al, 2003). In addition, data collection for unscheduled maintenance time requires considerable time and cost since the event occurs randomly or entirely unexpectedly.

Another serious problem with most performance measurement systems used in organizations is that, they often include too many different measures, which makes it difficult to understand the "big picture" (Keegan, Eilar \& Jones, 1989). Integration between measures is often problematic, and many papers have emphasized that organizations have no effective system that covers all necessary performance dimensions (Ghalayini \& Noble, 1996). This is why it is not always obvious how organizations should measure manufacturing performance. This has necessitated the usage of aggregate unit in obtaining the average cycle time and amount of product requested and produced.

In last, since the operating cycle time of some automated industry is carried out by an automatic machine, it is not possible to be considered as an ideal cycle time. Depending on automatic machine could lead to some difficulties in pursuing the ideal cycle time, as the performance of machine is fixed from time to time and has no improvement gap. 


\section{Methodology}

The research method used is first of all demonstrating the method used to simplify the quantification of product unit and the average cycle time of a production which comprises of several product types' mix. The subject studied is a group of six Autoclaves used to cure several types of composite products and the process cycle time of the curing process is fixed and unchangeable as per curing recipe. The understanding of working mechanism is helpful in clarifying and defining each of the elements in OEE computation. This is then used to modify definition and calculation of OEE to adapt the philosophy into any particular specific manufacturing environment. On top of that, computerized data is used to gather the amount of production rate and the curing time elapsed for all of the different product types. It is important to get the qualified data to ensure the accuracy of the result via the usage of computerized system. As per Ljungberg (1998) statement, the computerized data collection system is recommended regardless of high investment cost. On the other hand, the period for the data acquisition is set to be 60 days, which is around 9 weeks in calendar time. This decision of the period is based upon the recommendation of Abidian Inc. in the presentation for American Society for Quality (ASQ 1124), which stating that the data should be collected at least for 1 week, and ideally 1 month, to wipe out the effect of product mix. This is synchronized with the point of view from Capstone Metrics LLC (2011) which is stating that a properly integrated system of OEE information should be trended by month to present data relevant to typical enterprise level from top to bottom. Lastly, the demand rate requested by the customer is used to compare with the production rate to get the brief review on the planning practical.

Along this study, the ideal cycle time in the performance ratio computation is replaced by Takt time. For the purpose of Kaizen, Takt time will be revised from time to time so that to seek for a new target for better improvement. According to Rotaru (2008), the Takt time is a management tool to indicate at a glance whether production is ahead or behind it. In fact, its first use (in 1930s Germany) was in the aerospace industry, where product flow was extremely slow and repetitive activities are difficult to discern. This situation is very similar to the condition of the aerospace company being studied in this paper, which is currently experiencing the same problem too.

As such, the computerized data of Autoclave is acquired to obtain the cycle time for every product types being processed. The average of the cycle times is calculated per each unit of package (panel) and then compared with the Takt time computed to get the performance ratio. Over all of these, the Takt time is computed using the formula shown below:

Takt time $=$ Time available $/$ total customer demand 
Based on the formula shown above, both of the time available and demand within the observation period are calculated in monthly basis. Note that each type of the product mix being cured by the Autoclave comprises of different number of panel per one set and requires different cycle (curing) time. It is impractical and nonsense to evaluate different Takt time for each product type.

According to de Ron and Rooda in 2005, it's recommended to provide a simple and comprehensive metric for equipment performance rather than the detailed metrics. As a consequence of that, the total demand is computed in aggregate unit using the importance factor, which is based on the required cycle (curing) time by any particular product type over the total cycle time elapsed for 1 set of all product types ( 1 aggregate unit). This definition of calculating the aggregate unit is not only applicable on evaluation of historical performance but also for the calculation of scheduled production rate. This is helpful in reminding the schedulers if the production rate scheduled is achievable according to the capacity of the equipment. It is a must to formulate an effective lean process, as suggested by Puvanasvaran, Megat, Tang, Muhamad \& Hamouda (2009), on the employee's development aspect regarding how to unlock the infinite potential of their workforce. The same statement can be applied to the capacity equipment, which means the production should have utilized the equipment up to its maximum capability, implied in OEE, accordingly with customer demand.

According to Vorne Industries (2009), integration of Takt time into manufacturing operation is helpful to set real-time targets for production to show operators exactly where their work output should be at any point of time. Concept of Takt time is also responsible in reminding the process owner so that to keep their own equipment to operate in-aligned with the heartbeat of overall production line in order to achieve the customer demand. It's important to obtain the total time available to get an accurate Takt time as the heartbeat of production line. In achieving this, the availability of the equipment should be incorporated in the computation of time available. The performance ratio in this study is then defined in the formula shown below:

$$
\text { Performance ratio }=100 \%-[\mid \text { Average cycle time }- \text { Takt time } \mid / \text { Takt time }]
$$

Once the Takt time is calculated as per discussion above, the performance ratio is the percentage of average cycle time deviating from the heartbeat (Takt time) mentioned. The average cycle time is computed via dividing the total operating time in monthly basis by total production amount in aggregate unit in that particular month. In this study, the performance ratio of equipment with constant cycle time is dependent on the availability of equipment and total production unit scheduled on the equipment. In short, it helps in optimizing OEE value with neither overproduction nor delay in customer delivery, which both are the problems noted by Mileham et al. (1997) in the pursuit of high OEE value. 


\section{Performance ratio of equipment with constant proces time considering customer demand}

Based on literature review section, it's recommended to consider the customer demand in the computation of OEE and evaluate the performance of equipments with several product mixes in an aggregate unit. There is no such research as this before and there is a necessity to define performance ratio of equipment accordingly with their different characteristics. In this paper, the equipments studied are characterized with fixed cycle time within any particular product type from time to time. The following section will demonstrate the new definition of performance ratio incorporating the consideration of customer demand during evaluation of machine utilized by all product types in a single overall measurement.

As in Figure 1, the traditional computation approach of OEE has neglected the customer demand in pursuit of high OEE level, which will further contribute to overproduction. The product mixes being processed by any particular equipment will affect the measurement of OEE and some companies will evaluate different OEE measurement separately for each product type. At last, the equipment with constant cycle time is not possibly defined with ideal cycle time since it is always same as its cycle time and it's fixed.

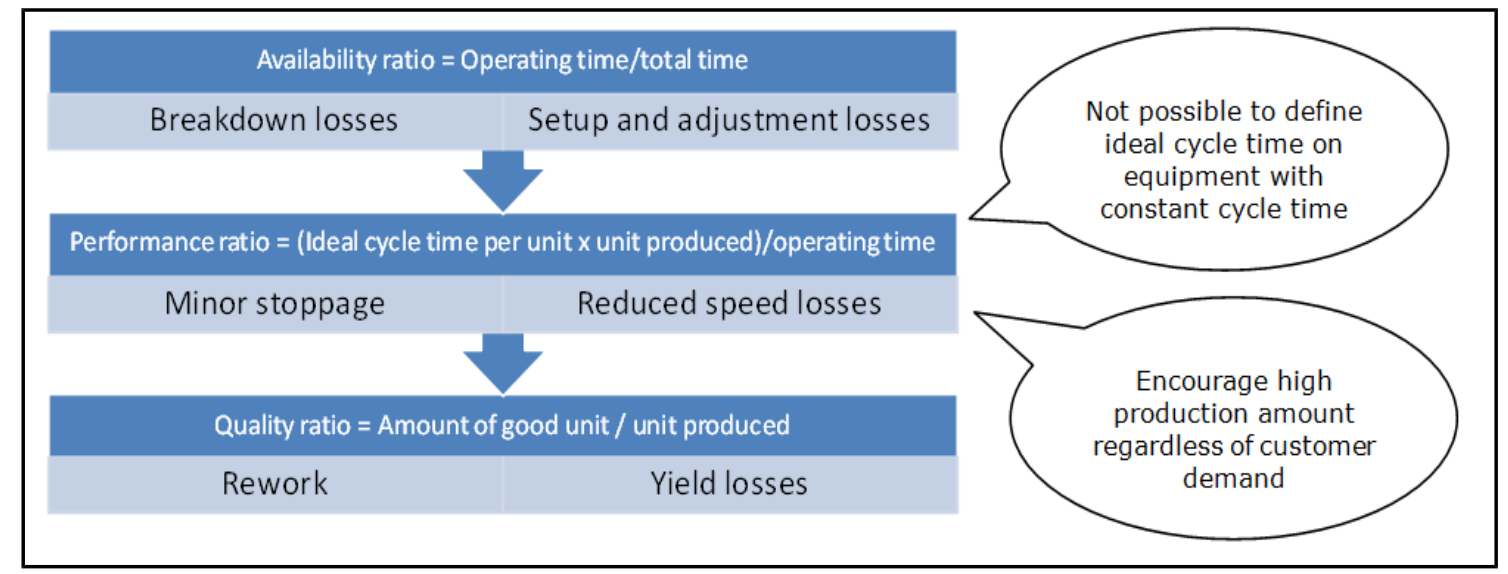

Figure 1. Calculation of performance ratio in traditional OEE approach

The new definition of performance ratio in this study, which can be seen in Figure 2, enables a single OEE measurement to cover all the product mixes in the equipment via aggregate average cycle time. This is also enabling the definition of ideal cycle time of equipment with constant cycle time through the maximization of product loading per each slot. Takt time is included in the calculation of performance ratio, which could reduce the possibility of overproduction at the same time pursuing high machine utilization. On top of that, the time available in the Takt time computation has incorporated the availability ratio so that the historical downtime data could be considered every time during scheduling of production, and this could prevent overestimation of the time available. 


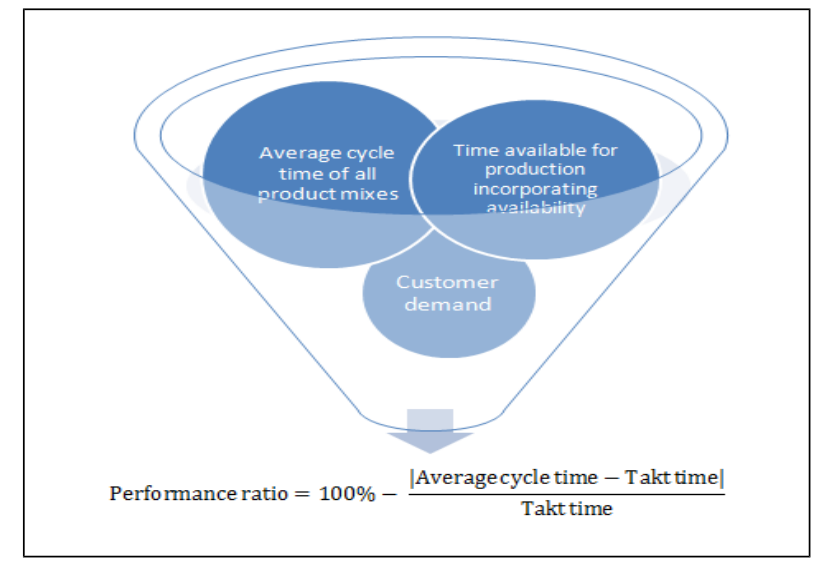

Figure 2. Performance ratio defined in this study and its considerations

\subsection{Average process time of product mix in aggregate unit}

The study has been carried out on six similar equipments which are curing several product types with different cycle time and different amount of panel per each set. In other words, product $A$ will always be cured with fixed cycle time, at any particular point of time, with maximum loading of $x$ panels per slot. However, the cycle time and number of loading will be different for product $B$. This contributes to different equipment utilization by different products regardless of same demand rate. Therefore, the importance factor which is based on cycle time of each product type is introduced to compute total amount of all packages in aggregate unit. Upon this definition, the weighting average method is used for the computation as shown below:

$$
\bar{x}=\frac{\sum_{i=1}^{n} w i x i}{\sum_{i=1}^{n} w i}
$$

Equation 3. Computation of product in aggregate unit

Where: $\mathrm{n}=$ number of product types

$\mathrm{W}=$ Constant cycle time of particular product type

$X=$ number of product unit

$\overline{\mathrm{X}}=$ Aggregate unit of product

Through the introduction of weighting average method in computation of aggregate number of unit processed (cured) in Autoclaves, the average cycle time and Takt time are calculated for the performance ratio of equipment with constant process time. Within this definition, the demand of product to be cured as shown in Appendix $A$ is multiplied by weighting factor as in Appendix B.

The cycle time in Appendix B is constant and fixed cycle time for each set of the package types. It's unchangeable as per requirement of curing recipe. The actual production amount 
shown in the table is multiplied with the cycle time to obtain the total production time elapsed. On the other hand, the weighting factor for same package varies from week to week since its process time is not in the same portion over the total process time of all packages in that particular week. This is due to different product mixes are scheduled for production in that particular week and hence the use of weighting factor is to quantify the percentage of that particular package in one aggregate unit. The demand (scheduled production rate) and actual production amount are then multiplied by the weighting factor and summed up separately to obtain the total scheduled rate and actual production amount in aggregate unit respectively. All of the data are then summarized in Table: 1 shown below:

\begin{tabular}{|c|c|c|c|c|c|c|c|c|c|c|}
\hline \multicolumn{2}{|c|}{ Description } & Week 1 & Week 2 & Week 3 & Week 4 & Week 5 & Week 6 & Week 7 & Week 8 & Week 9 \\
\hline \multirow{3}{*}{$\begin{array}{l}\text { Machine } \\
\text { utilization }\end{array}$} & Production time & 738.40 & 724.38 & 723.12 & 700.15 & 773.80 & 673.70 & 774.75 & 803.98 & 775.13 \\
\hline & Production rate & 1.99 & 2.08 & 1.87 & 1.98 & 1.84 & 1.60 & 2.02 & 2.10 & 1.95 \\
\hline & $\begin{array}{c}\text { Average Cycle } \\
\text { Time }\end{array}$ & 370.95 & 249.01 & 387.17 & 354.44 & 420.24 & 422.17 & 383.82 & 382.20 & 398.44 \\
\hline \multirow{5}{*}{$\begin{array}{l}\text { Limit } \\
\text { Capacity }\end{array}$} & Total time & 1008 & 1008 & 1008 & 1008 & 1008 & 1008 & 1008 & 1008 & 1008 \\
\hline & $\begin{array}{c}\text { Average } \\
\text { availability }\end{array}$ & $70.54 \%$ & $70.54 \%$ & $70.54 \%$ & $70.54 \%$ & $73.94 \%$ & $73.94 \%$ & $73.94 \%$ & $73.94 \%$ & $73.94 \%$ \\
\hline & Time available & 711.04 & 711.04 & 711.04 & 711.04 & 745.36 & 745.36 & 745.36 & 745.36 & 745.36 \\
\hline & Demand rate & 2.07 & 2.20 & 2.21 & 2.08 & 2.10 & 1.70 & 2.18 & 1.80 & 1.81 \\
\hline & Takt Time & 342.88 & 323.20 & 321.83 & 341.08 & 354.15 & 438.57 & 341.81 & 414.70 & 412.34 \\
\hline
\end{tabular}

Table 1. Average cycle time and Takt time of six Autoclaves in nine weeks

Note that both of the production rate and demand rate are calculated in aggregate unit whereas the production time is summation of cycle time of each package multiplies with number of set produced. On the other hand, the total time is summation of weekly calendar time in hour for 6 Autoclaves. Due to simplification reason, the availability for week 1-4 and week 5-9 are calculated from percentage of total monthly operation time over total calendar time in a month (total calendar approach) and is not further explained in this paper. The time available in the computation of Takt time has been considering the availability so that the capacity of equipment is not over-estimated.

Once the Takt time and average cycle time are calculated, formula 2 is used to obtain the performance ratio for the OEE computation.

The comparison between Takt time and average cycle time is recommended in the computation of OEE. This is because neither over-production nor late delivery of customer demand is neglected in the pursuit of high and efficient machine utilization. This is clearly demonstrated by recalling back to Table 1 and Table 2 on the aggregate unit and time, where overproduction (production rate is more than the demand rate) happens whenever average cycle time is shorter than Takt time and shortage of production occurs in the week when Takt time is shorter than average cycle time. However, there is an exception in week 6 when the Takt time is larger than average cycle time but still experiencing the shortage of production. This is probably due to the inaccuracy in the production time gathered which could be imagined in the condition at 
which the curing process was done yet waiting for operators to unload the panels from Autoclave.

\begin{tabular}{|l|r|r|r|r|r|r|r|r|r|}
\hline \multirow{2}{*}{\multicolumn{1}{|c}{ Time }} & \multicolumn{4}{|c|}{ January } & \multicolumn{5}{c|}{ February } \\
\cline { 2 - 11 } & Week 1 & Week 2 & \multicolumn{1}{|c|}{ Week 3 } & Week 4 & Week 5 & Week 6 & \multicolumn{1}{c|}{ Week 7 } & Week 8 & Week 9 \\
\hline Average cycle time & 370.94 & 349.01 & 387.17 & 354.44 & 420.24 & 422.17 & 383.82 & 382.20 & 398.44 \\
\hline Takt time & 342.88 & 323.20 & 321.83 & 341.08 & 354.15 & 438.57 & 341.81 & 414.70 & 412.34 \\
\hline Performance loss & $8.18 \%$ & $7.99 \%$ & $20.30 \%$ & $3.92 \%$ & $18.66 \%$ & $3.74 \%$ & $12.29 \%$ & $7.84 \%$ & $3.37 \%$ \\
\hline Performance ratio & $91.82 \%$ & $92.01 \%$ & $79.70 \%$ & $96.08 \%$ & $81.34 \%$ & $96.26 \%$ & $87.71 \%$ & $92.16 \%$ & $96,63 \%$ \\
\hline
\end{tabular}

Table 2. Weekly performance ratio computed using average cycle time and Takt time.

If the performance ratio computed in traditional approach as shown in Figure 1 , it will be always $100 \%$ since the ideal cycle time is same as cycle time see Appendix A. The performance ratio in traditional approach is calculated by summing all of the multiplications of curing time of a particular product type with their corresponding production rate and then divided by total operation time. Customer demand is not incorporated in the traditional approach, as shown in Figure 1, and this will lead to overproduction of backlog in delivery. Through the new definition of performance ratio in this study, it was discovered that even for those equipments with constant cycle time, they are not actually performing at satisfying speed or rate, and still subject to a large gap of improvement. This could be visualized in the following section.

\subsection{Implications}

From the analysis and explanation defined above, the new definition of performance ratio is valid for the application of coarse capacity review. The Takt time in performance ratio implies the maximum limit of capacity could be performed by equipment after considering the availability whereas the average cycle time of performance ratio indicates the historical performance of equipment corresponding to customer demand. Transforming the results in Table 1 and Table 2 above into the chart shown in Figure 3 will illustrate the comparison between workload and capacity of equipments.

As shown in Figure 3 the average capacity limits indicated in line shouldn't be exceeded by the production rate scheduled. The actual machine utilization is measured using average cycle time and compared with the limit from time to time in examining the machine performance. The comparison between these data of performance ratio enables planner of production in balancing demand with capacity of equipment to avoid overproduction and shortage of delivery. 


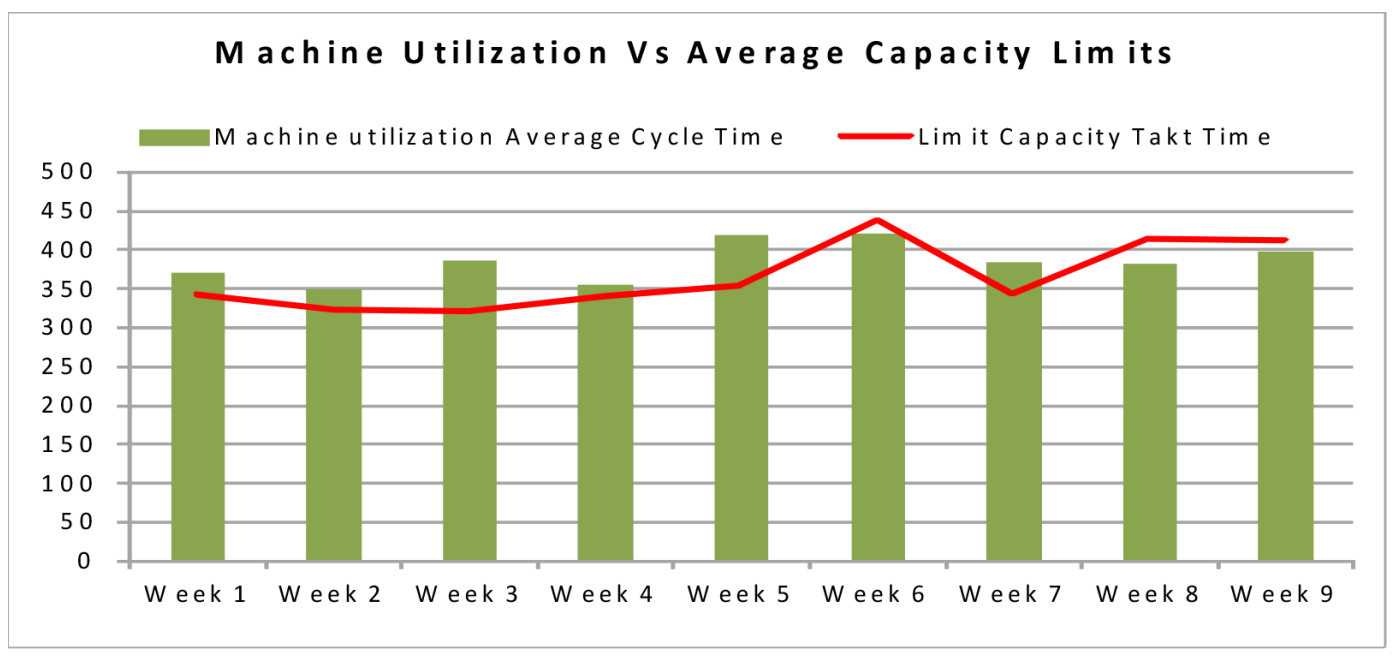

Figure 3. Comparison of workload and capacity allowable using performance ratio

It's actually difficult to evaluate the planner's efficiency in most of the cases since the production scheduling is dependent on the capacity of equipment, customer demand on each of the product types, the product mix and its quantity. However, performance ratio as defined in this study can be used as an examination of production planning and evaluation of machinery performance.

As the historical planning evaluation as illustrated in Figure 3, planner should increase the amount of products to be cured in week 10 since the workload processed in past few weeks is less than the limit of the equipment capacity. This has implied in sub-efficient planning on the equipment which contributed to under-utilization of equipment (waste). The performance ratio should be updated from time to time and revised periodically so that to provide a reference or guidance especially in the scheduling of production rate in the future. The data in Table 1 and Table 2 are further summarized into monthly basis for ease of monthly production scheduling as shown below.

Note that the aggregate unit shown above is calculated on monthly basis where the weighting factor of each package is calculated over total cycle time of all packages in a month. This has contributed to smaller portion of that particular package as an aggregate unit and hence the summation of monthly aggregate unit is not the same as the total aggregate unit in Table 1.

The historical actual data shows that the rate scheduled in January and February are higher than the maximum rate could be produced, that is, 6.18 and 5.81 aggregate units in contrast to 5.83 and 5.62 aggregate units respectively. The same condition is visualized in Figure 3 from week 1 to week 9 which had experienced serious shortage of production.

Note that the main concern of using this analytical method is the scheduled production rate in the future which is indicated as a question mark '?'. Implication from here is that the data can be averaged to serve as reference in the future, as shown in Table 3, where the scheduled production rate in the following month indicated as unknown value '?', it shouldn't be more 
than 5.73 aggregate units to avoid over-burden of equipment. Even though most of the workloads in February shown in Figure 3 (week 5-week 9) are less than the capacity limit, but it's clear to be concluded in Table 3 that backlog occurs. The main reason here is the backlog occurs in week 5 and week 7 couldn't be covered by other few weeks and corresponding actions have to be taken.

\begin{tabular}{|c|c|c|c|c|}
\hline Time & Description & Jan & Feb & Average \\
\hline \multirow{3}{*}{$\begin{array}{l}\text { Average } \\
\text { Cycle time } \\
\text { (Hours) }\end{array}$} & Operating time (Hour) & 2534.66 & 2852.03 & \\
\hline & Total production (Set) & 4.70 & 5.19 & \\
\hline & Average cycle time & 539.82 & 549.46 & 544.64 \\
\hline \multirow{3}{*}{ Time available } & $24 \times 7$ & 4464.00 & 4176.00 & 4320 \\
\hline & Availability & $70.54 \%$ & $73.94 \%$ & $72.24 \%$ \\
\hline & Time Available (Hour) & 3148.90 & 3087.90 & 3120.85 \\
\hline \multirow{2}{*}{$\begin{array}{c}\text { Rate } \\
\text { comparison }\end{array}$} & Theorical rate produced & 5.83 & 5.62 & 5.73 \\
\hline & Total MPS Rate & 6.18 & 5.81 & ? \\
\hline
\end{tabular}

Table 3. Historical data as reference of future scheduling

As such, the performance ratio incorporating the customer demand and availability (time available) can be applied on those equipments with constant cycle time in the pursuit of high OEE value. In alignment with the point of view from Vorne Industries (2009) stating that integration of Takt time into manufacturing operation is helpful in setting real-time targets of work output should be. The integration stated is literally done in this study through the introduction of Takt time in performance measurement. It's important and essential so that it's not leading to the issue of over-production or over-burden of equipment.

However, the proposed concept in this paper is limited only on those equipments with constant cycle time. The invariably improved cycle time of this equipment can only be evaluated using customer demand in performance ratio. The definition of performance ratio in this paper couldn't be applied in the equipment with varying cycle time and fluctuating customer demand from time to time. This is because the ideal cycle time, average cycle time, and customer demand (Takt time) are the three elements to be considered for this equipment type in contrast to only 2 elements in the equipment studied in this paper, which are average cycle time and customer demand only.

\section{Conclusion}

This paper focused on the integration of Takt time into the overall equipment effectiveness (OEE) of Autoclaves which cure product at constant cycle time. The performance ratio of such equipment as this was evaluated as $100 \%$ in traditional approach all the time because the cycle time is always same as the ideal cycle time. Besides that, the pursuit of high OEE value in traditional approach will usually lead to overproduction especially during low-demand period. New definition of performance ratio introduced in this study regarding to the limitations stated. Within this, neither overproduction nor shortage of production is allowed in high utilization of equipment since $100 \%$ of performance ratio can only be achieved whenever the Takt time is 
exactly same as the average cycle time. Over all of this, a method in providing simple and comprehensive measurement, as recommended by de Ron and Rooda (2005), has been introduced using the weighted averaging method. Several product mixes with different amounts are covered by an aggregate unit to provide a strategic overview of production of equipments.

\section{References}

Abidian inc. (2007). Overall Equipment (service) Effectiveness. OEE presentation for American Society for Quality, 1124, 1-13.

Bamber, C.J., Castka, P., Sharp, J.M., \& Motara, Y. (2003). Cross-functional team working for overall equipment effectiveness (OEE). Journal of Quality in Maintenance Engineering, 9(3), 223-238. http://dx.doi.org/10.1108/13552510310493684

Capstone Metric, (2011). Overall Equipment Effectiveness: A general discussion on its benefits. 2001-2011 Capstones Metrics LLC, pp. 1-7.

Dal, B., Tugwell, P., \& Greatbanks, R. (2000). Overall equipment effectiveness as a measure of operational improvement: a practical analysis. International Journal of Operations \& Production Management,20(12), 1488-1502. http://dx.doi.org/10.1108/01443570010355750

de Ron, A.J., \& Rooda, J.E. (2005). Equipment effectiveness: OEE revisited. IEEE Transactions on Semiconductor Manufacturing, 18(1), 190-196. http://dx.doi.org/10.1109/TSM.2004.836657

Ericsson, J. (1997). Disruption Analysis - An important Tool in Lean Production. Department of Production and Materials Engineering, Lund University, Lund.

Gagnon, M.A., \& Michael, J.H. (2003). Employee Strategic Alignment at a Wood Manufacturer: An Exploratory Analysis Using Lean Manufacturing. Forest Products Journal, 53(10), 24-29.

Ghalayini, A.M., \& Noble, J.S. (1996). The changing basis of performance measurement. International Journal of Operations \& Production Management, 16(8), 63-80. http://dx.doi.org/10.1108/01443579610125787

Hansen, R.C. (2001). Overall Equipment Effectiveness: A Powerful Production Maintenance Tool for Increased Profits. New York, NY: Industrial Press Inc.

Hayes, R.H., \& Pisano, G.P. (1994). Beyond world class: the new manufacturing strategy. Harvard Business Review, January-February, 77-86.

Hilmola, O.P. (2005). Total Productivity Measurement and Competitiveness: Towards Ensuring Sustainable Business Performance in Manufacturing Organizations: A Literature Review. Int J Process Management and Benchmarking, 1(1), 45-62.http://dx.doi.org/10.1504/IJPMB.2005.006111 
Jonsson, P., \& Lesshammar, M. (1999). Evaluation and improvement of manufacturing performance measurement systems - the role of OEE. International Journal of Operations \& Production Management, 19(1), 55-78. http://dx.doi.org/10.1108/01443579910244223

Keegan, D.P., Eilar, R.G., \& Jones, C.R (1989). Are your performance measures obsolete? Management Accounting, 71, June, 45-50.

Kenis, P. (2006). Waiting lists in Dutch health care. An analysis from an organization theoretical perspective. Journal of Health Organization and Management, 20(4), 294-308. http://dx.doi.org/10.1108/14777260610680104

Ljungberg, O. (1998). Measurement of overall equipment effectiveness as a basic for TPM activities. International Journal of Operations \& Production Management, 18(5), 495-507. http://dx.doi.org/10.1108/01443579810206334

Mileham, A.R., Culley, S.J., Mclntosh, R.I., Gest, G.B., \& Owen, G.W. (1997). Set-up reduction (SUR) beyond total productive maintenance (TPM). Proceedings of Instituition of Mechanical Engineers, 211 Part b, 253-260. http://dx.doi.org/10.1243/0954405971516248

Nakajima S. (1998). Introduction to TPM. Portland: Productivity Press.

Nakajima, S. (1988). Introduction to TPM. Cambridge, MA: Productivity Press.

Puvanasvaran, A.P., Megat, H., Tang, S.H, Muhamad, M.R, \& Hamouda, A.M.S. (2009). Lean process management implementation through enhanced problem solving capability. Journal of industrial engineering and management, 3(3), 447-493.

Rotaru, A. (2008). All about Takt time. Fascicle of management and Technological Engineering, VII(XVII), 2688-2691.

Schmenner, R.W., \& Vollmann, T.E. (1994). Performance measures: gaps, false alarms and the 'usual suspects'. International Journal of Operations \& Production Management, 14(12), 58-69. http://dx.doi.org/10.1108/01443579410072391

Shah, R., \& Ward, P.T. (2007). Defining and developing measures of lean production. Journal of Operations Management, 25, 785-805. http://dx.doi.org/10.1016/j.jom.2007.01.019

Sweeney, M.T. (1990, June). Breakthrough to World Class Manufacturing: A Strategy for the Transformation. 5th International Conference on Manufacturing Strategy, UK Operations Management Association.

Tajiri, M., \& Gotoh, F. (1992). TPM Implementation: A Japanese Approach. New York, NY: McGraw-Hill. 
Vorne Industries, Inc. (2009). Takt Time. Retrieved from http://www.vorne.com/pdf/lean-brieftakt-time.pdf

Wauters, F., \& Mathot, J. (2007). Overall Equipment Effectiveness. ABB Inc, Retrieved from http://www.abb.com/oee.pdf

Williamson, R.M. (2006). Using Overall Equipment Effectiveness: The metric and the measure. Strategic Work System, Inc., Columbus NC 28722, 1-6.

Wireman, T. (2004). Total Productive Maintenance. $2^{\text {nd }}$ edition.

Wong, Y.C., Wong, K.Y., \& Ali, A. (2009). A study on lean implementation in the Malaysian electrical and electronic industry. European Journal of Scientific Research, 38(4), 521-535.

\section{Appendix A}

Demand rate, actual production amount and cycle time of some products cured in Autoclaves

\begin{tabular}{|c|c|c|c|c|c|c|c|c|c|c|}
\hline \multicolumn{2}{|l|}{ PROJECT } & \multirow{2}{*}{$\begin{array}{r}\text { WK1 } \\
9.0\end{array}$} & \multirow{2}{*}{$\begin{array}{r}\text { WK2 } \\
12.0\end{array}$} & WK3 & WK4 & WK5 & WK6 & WK7 & WK8 & WK9 \\
\hline \multirow{3}{*}{ LEADING EDGE } & Demand & & & 12.0 & 6.0 & 9.0 & 9.0 & 12.0 & 9.0 & 12.0 \\
\hline & Actual & 10.5 & 10.5 & 10.5 & 7.0 & 7.0 & 7.0 & 10.5 & 10.5 & 10.5 \\
\hline & Cycle time & 3.33 & 3.33 & 3.33 & 3.33 & 3.33 & 3.33 & 3.33 & 3.33 & 3.33 \\
\hline \multirow{3}{*}{ TRAILING EDGE } & Demand & 9.0 & 9.0 & 12.0 & 6.0 & 12.0 & 9.0 & 9.0 & 12.0 & 12.0 \\
\hline & Actual & 11.0 & 10.0 & 9.7 & 8.6 & 5.7 & 9.7 & 8.6 & 8.9 & 10.0 \\
\hline & Cycle time & 0.90 & 0.90 & 0.90 & 0.90 & 0.90 & 0.90 & 0.90 & 0.90 & 0.90 \\
\hline \multirow{3}{*}{ AILERON } & Demand & 9.0 & 12.0 & 9.0 & 6.0 & 12.0 & 9.0 & 12.0 & 9.0 & 12.0 \\
\hline & Actual & 9.0 & 9.0 & 9.0 & 8.7 & 4.9 & 9.6 & 9.0 & 9.0 & 10.0 \\
\hline & Cycle time & 0.90 & 0.90 & 0.90 & 0.90 & 0.90 & 0.90 & 0.90 & 0.90 & 0.90 \\
\hline \multirow{3}{*}{ UNDERWING } & Demand & 9.0 & 12.0 & 9.0 & 9.0 & 9.0 & 9.0 & 9.0 & 9.0 & 9.0 \\
\hline & Actual & 9.0 & 12.0 & 12.0 & 9.0 & 9.0 & 9.0 & 9.0 & 12.0 & 9.0 \\
\hline & Cycle time & 1.28 & 1.28 & 1.28 & 1.28 & 1.28 & 1.28 & 1.28 & 1.28 & 1.28 \\
\hline \multirow{3}{*}{ FALSEWORK } & Demand & 8.0 & 12.0 & 12.0 & 6.0 & 12.0 & 8.0 & 10.0 & 12.0 & 12.0 \\
\hline & Actual & 9.0 & 9.0 & 9.0 & 9.0 & 8.0 & 7.0 & 6.0 & 4.0 & 9.0 \\
\hline & Cycle time & 2.22 & 2.22 & 2.22 & 2.22 & 2.22 & 2.22 & 2.22 & 2.22 & 2.22 \\
\hline \multirow{3}{*}{ OVERWING } & Demand & 10.0 & 10.0 & 10.0 & 8.0 & 10.0 & 8.0 & 10.0 & 10.0 & 10.0 \\
\hline & Actual & 12.0 & 12.0 & 12.0 & 8.0 & 10.0 & 8.0 & 10.0 & 8.0 & 11.5 \\
\hline & Cycle time & 2.98 & 2.98 & 2.98 & 2.98 & 2.98 & 2.98 & 2.98 & 2.98 & 2.98 \\
\hline \multirow{3}{*}{ AILERON SHARKLET } & Demand & 1.0 & - & 1.0 & 1.0 & 1.0 & 1.0 & - & - & - \\
\hline & Actual & 1.0 & - & 1.0 & - & 2.0 & 1.0 & 1.0 & - & - \\
\hline & Cycle time & 0.90 & & 0.90 & & 0.90 & 0.90 & 0.90 & & \\
\hline \multirow{3}{*}{ SPOILER } & Demand & 9.0 & 10.5 & 10.5 & 7.5 & 10.5 & 9.0 & 10.5 & 10.5 & 10.5 \\
\hline & Actual & 11.2 & 9.5 & 10.7 & 8.0 & 11.0 & 9.1 & 8.0 & 11.0 & 11.2 \\
\hline & Cycle time & 8.80 & 8.80 & 8.80 & 8.80 & 8.80 & 8.80 & 8.80 & 8.80 & 8.80 \\
\hline \multirow{3}{*}{ A320 MOVEABLE FAIRING } & Demand & 8.0 & 10.0 & 10.0 & 6.0 & 8.0 & 8.0 & 10.0 & 8.0 & 10.0 \\
\hline & Actual & 8.7 & 8.3 & 7.5 & 6.3 & 6.2 & 5.2 & 8.3 & 7.3 & 8.7 \\
\hline & Cycle time & 2.08 & 2.08 & 2.08 & 2.08 & 2.08 & 2.08 & 2.08 & 2.08 & 2.08 \\
\hline \multirow{3}{*}{ A320 AFT FIX FAIRING } & Demand & 8.0 & 8.0 & 8.0 & 6.0 & 8.0 & 8.0 & 8.0 & 8.0 & 8.0 \\
\hline & Actual & 8.2 & 8.0 & 7.2 & 6.2 & 8.0 & 6.7 & 6.8 & 8.2 & 4.5 \\
\hline & Cycle time & 1.75 & 1.75 & 1.75 & 1.75 & 1.75 & 1.75 & 1.75 & 1.75 & 1.75 \\
\hline \multirow{3}{*}{ A321 MOVEABLE FAIRING } & Demand & 2.0 & 2.0 & 2.0 & 1.0 & 2.0 & 2.0 & 2.0 & 2.0 & 1.0 \\
\hline & Actual & 1.5 & 1.8 & 1.0 & 0.8 & 2.0 & 1.3 & 1.3 & 1.7 & 1.3 \\
\hline & Cycle time & 2.08 & 2.08 & 2.08 & 2.08 & 2.08 & 2.08 & 2.08 & 2.08 & 2.08 \\
\hline \multirow{3}{*}{ A321 FIX FAIRING } & Demand & 2.0 & 2.0 & 2.0 & 1.0 & 2.0 & 1.0 & 2.0 & 2.0 & 2.0 \\
\hline & Actual & 0.7 & 2.2 & 0.8 & 0.7 & 1.3 & 1.0 & 1.0 & 1.8 & 2.0 \\
\hline & Cycle time & 1.75 & 1.75 & 1.75 & 1.75 & 1.75 & 1.75 & 1.75 & 1.75 & 1.75 \\
\hline & Demand & 8.0 & 10.0 & 10.0 & 6.0 & 10.0 & 8.0 & 10.0 & 8.0 & 10.0 \\
\hline A320 TOP COVER & Actual & 10.5 & 9.3 & 7.3 & 6.8 & 3.7 & 6.5 & 8.5 & 8.0 & 9.0 \\
\hline & Cycle time & 1.75 & 1.75 & 1.75 & 1.75 & 1.75 & 1.75 & 1.75 & 1.75 & 1.75 \\
\hline & Demand & 2.0 & 2.0 & 2.0 & 1.0 & 2.0 & 2.0 & 2.0 & 2.0 & 1.0 \\
\hline A321 TOP COVER & Actual & 1.3 & 2.2 & 2.0 & 1.2 & 3.0 & 1.5 & 1.8 & 2.0 & 2.0 \\
\hline & Cycle time & 1.75 & 1.75 & 1.75 & 1.75 & 1.75 & 1.75 & 1.75 & 1.75 & 1.75 \\
\hline
\end{tabular}




\section{Appendix B}

Weighting factor of each package type in occupying equipment workload

\begin{tabular}{|c|c|c|c|c|c|c|c|c|c|c|c|c|c|c|c|c|c|c|c|}
\hline \multicolumn{2}{|l|}{ PROJECT } & WK1 & $\begin{array}{l}\text { Weight } \\
\text { per set } \\
\text { (1) }\end{array}$ & WK2 & $\begin{array}{l}\text { Weight } \\
\text { per set } \\
\text { (2) }\end{array}$ & WKS & $\begin{array}{c}\text { Weight } \\
\text { per set } \\
\text { (3) }\end{array}$ & WKA & $\begin{array}{l}\text { Weight } \\
\text { per set } \\
\text { (4) }\end{array}$ & Wis & $\begin{array}{l}\text { Weight } \\
\text { per set } \\
\text { (5) }\end{array}$ & wik6 & $\begin{array}{l}\text { Weight } \\
\text { per set } \\
\text { (6) }\end{array}$ & Whe & $\begin{array}{l}\text { Waight } \\
\text { perset } \\
\text { (7) }\end{array}$ & WK8 & $\begin{array}{l}\text { Weight } \\
\text { perset } \\
\text { (8) }\end{array}$ & WK9 & $\begin{array}{l}\text { Weight } \\
\text { per set } \\
\text { (9) }\end{array}$ \\
\hline \multirow[t]{2}{*}{ LEATING BDGE } & $\begin{array}{l}\text { Denand } \\
\text { Ađtual }\end{array}$ & $\begin{array}{r}9.0 \\
10.5\end{array}$ & & $\begin{array}{l}120 \\
10.5\end{array}$ & & $\begin{array}{l}120 \\
10.5\end{array}$ & & $\begin{array}{l}6.0 \\
7.0\end{array}$ & & $\begin{array}{l}9.0 \\
7.0\end{array}$ & & $\begin{array}{l}9.0 \\
7.0\end{array}$ & & $\begin{array}{l}12.0 \\
10.5\end{array}$ & & $\begin{array}{r}9.0 \\
10.5\end{array}$ & & $\begin{array}{l}12.0 \\
10.5\end{array}$ & \\
\hline & Godetime & 3.33 & 0.011 & 3.33 & 0.010 & 3.33 & 0.009 & 3.33 & 0.011 & 3.33 & 0.009 & 3.33 & 0.008 & 3.33 & 0.010 & 3.33 & 0.008 & 3.33 & 0.008 \\
\hline \multirow[t]{2}{*}{ TRALING BDGE } & $\begin{array}{l}\text { Demand } \\
\text { Adudul }\end{array}$ & $\begin{array}{r}90 \\
11.0\end{array}$ & & $\begin{array}{r}90 \\
10.0\end{array}$ & & $\begin{array}{r}120 \\
9.7\end{array}$ & & $\begin{array}{l}60 \\
8.6\end{array}$ & & $\begin{array}{r}12.0 \\
5.7\end{array}$ & & $\begin{array}{l}9.0 \\
9.7\end{array}$ & & $\begin{array}{r}9.30 \\
8.0 \\
8.6\end{array}$ & & $\begin{array}{r}120 \\
8.9\end{array}$ & & $\begin{array}{l}.0 .0 \\
12.0 \\
10.0\end{array}$ & \\
\hline & adetime & 0.90 & 0.003 & 0.90 & $@ 3$ & 0.90 & 03 & 0.90 & 0.003 & 0.90 & 0.003 & 0.90 & 0.002 & 0.90 & 03 & 0.90 & $\underline{Q}$ & 0,90 & 0.002 \\
\hline \multirow[t]{2}{*}{ AILRON } & $\begin{array}{l}\text { Demand } \\
\text { Ađtual }\end{array}$ & $\begin{array}{l}9.0 \\
9.0\end{array}$ & & $\begin{array}{r}120 \\
9.0\end{array}$ & & $\begin{array}{l}9.0 \\
9.0\end{array}$ & & $\begin{array}{l}60 \\
87\end{array}$ & & $\begin{array}{r}12.0 \\
4.9\end{array}$ & & $\begin{array}{l}9.0 \\
9.6\end{array}$ & & $\begin{array}{r}12.0 \\
9.0\end{array}$ & & $\begin{array}{l}9.0 \\
9.0\end{array}$ & & $\begin{array}{l}12.0 \\
10.0\end{array}$ & \\
\hline & Gycletime & 0.90 & 0.003 & 0.90 & 03 & 0.90 & 03 & 0,90 & 0.003 & 0.90 & 0.003 & 0,90 & 02 & 0.90 & 003 & 0.90 & 02 & 0.90 & 0.002 \\
\hline \multirow{2}{*}{ UNDERWING } & $\begin{array}{l}\text { Denand } \\
\text { AđLual }\end{array}$ & $\begin{array}{l}90 \\
90\end{array}$ & & $\begin{array}{l}120 \\
120\end{array}$ & & $\begin{array}{r}9.0 \\
120\end{array}$ & & $\begin{array}{l}9.0 \\
9.0\end{array}$ & & $\begin{array}{l}9.0 \\
9.0\end{array}$ & & $\begin{array}{l}9.0 \\
90\end{array}$ & & $\begin{array}{r}9.0 \\
9.0\end{array}$ & & $\begin{array}{l}90 \\
120\end{array}$ & & $\begin{array}{l}9.0 \\
9.0\end{array}$ & \\
\hline & Gidetime & $\begin{array}{r}1.28 \\
80\end{array}$ & 0.004 & $\begin{array}{l}1.28 \\
120\end{array}$ & 0.004 & $\begin{array}{l}1.28 \\
120\end{array}$ & 0.004 & 1.28 & 0.004 & $\begin{array}{l}1.28 \\
120\end{array}$ & 0.004 & $\begin{array}{r}1.28 \\
80\end{array}$ & 0.03 & $\begin{array}{r}1.28 \\
100\end{array}$ & 0.004 & 1.28 & 0.003 & 1.28 & 0.003 \\
\hline \multirow[t]{2}{*}{ FALE: } & $\begin{array}{l}\text { Demand } \\
\text { Ađud }\end{array}$ & 90 & & 90 & & 90 & & 90 & & 8.0 & & 7.0 & & 6.0 & & 4.0 & & 9.0 & \\
\hline & godetime & 2.22 & 0.007 & 2.22 & 0.007 & 2.22 & 0.006 & 2.22 & 0.007 & 2.22 & 0.006 & 2.22 & 0.005 & 2.22 & 0.006 & 2.22 & 0.006 & 2.22 & 0.005 \\
\hline \multirow{4}{*}{ OVERAING } & Demand & 100 & & 100 & & 100 & & 80 & & 10.0 & & 80 & & 10.0 & & 10.0 & & 10.0 & \\
\hline & $\begin{array}{l}\text { Adud } \\
\text { adetetme }\end{array}$ & $\begin{array}{r}120 \\
2.98\end{array}$ & 00010 & $\begin{array}{r}120 \\
2.98\end{array}$ & 0.009 & $\begin{array}{r}120 \\
298\end{array}$ & 0008 & $\begin{array}{r}80 \\
298\end{array}$ & 0000 & 2.98 & 0008 & $\begin{array}{r}8.0 \\
2.98\end{array}$ & 0.007 & $\begin{array}{l}10.0 \\
298\end{array}$ & 0.09 & $\begin{array}{l}8.0 \\
2.98\end{array}$ & 0008 & $\begin{array}{l}11.5 \\
298\end{array}$ & 0007 \\
\hline & Derand & 1.0 & & & & & & 1.0 & & 1.0 & & 1.0 & & & & & & & \\
\hline & Acual & 10 & & - & & 1.0 & & & & 2.0 & & 1.0 & & 1.0 & & - & & - & \\
\hline \multirow{4}{*}{ SPOILER } & Gocletime & 0.90 & 0.003 & & - & 0.90 & 0.003 & & - & 0.90 & 0.003 & 0.90 & 0.002 & 0.90 & 0.003 & & - & & \\
\hline & Demand & 9.0 & & 10.5 & & 10.5 & & 7.5 & & 10.5 & & 9.0 & & 10.5 & & 10.5 & & 10.5 & \\
\hline & Actual & 112 & & 95 & & 10.7 & & 80 & & 11.0 & & 9.1 & & 8.0 & & 11.0 & & 11.2 & \\
\hline & Goletime & 8.80 & 0.029 & 8.80 & 0.027 & 8.80 & .025 & 8.80 & 0.029 & 8.80 & 0.025 & 8.80 & 0.022 & 8.80 & 0.026 & 8.80 & .022 & 8.80 & 0.020 \\
\hline \multirow{2}{*}{ AB2O MOVEABE FAIRING } & Demand & 80 & & 700 & & 100 & & 60 & & 8.0 & & 80 & & 10.0 & & 80 & & 10.0 & \\
\hline & & 8.7 & $m$ & 83 & n & 7.5 & $m c$ & 63 & & 6.2 & & 5.2 & & 8.3 & & 7.3 & & 8.7 & \\
\hline \multirow{3}{*}{ AB20 AFTFIX FAIRING } & acletime & 2.08 & 0.007 & 2.08 & 06 & 208 & .006 & 208 & 0.007 & 2.08 & 06 & 208 & 005 & 208 & 006 & 208 & .005 & 208 & 0.005 \\
\hline & Demand & 8.0 & & 80 & & 8.0 & & 60 & & 8.0 & & 80 & & 8.0 & & 8.0 & & 8.0 & \\
\hline & & 82 & & 8.0 & & 7.2 & & 6.2 & $m a$ & 8.0 & & 6.7 & & 6.8 & & 8.2 & & 4.5 & $\mathrm{ng}$ \\
\hline \multirow{3}{*}{ ABZ1 MOVEABE FAIRING } & Demand & $\frac{110}{20}$ & & $\frac{1120}{20}$ & & $\frac{150}{20}$ & & $\frac{1.15}{1.0}$ & & $\frac{15}{2.0}$ & & $\frac{1.15}{20}$ & & $\frac{1.15}{2.0}$ & & $\frac{1.15}{20}$ & & $\frac{15}{1.0}$ & 0.004 \\
\hline & Ađual & 1.5 & & 1.8 & & 1.0 & & 08 & & 2.0 & & 1.3 & & 13 & & 1.7 & & 1.3 & \\
\hline & Godetime & 2.08 & 0.007 & 2,08 & 0.006 & 208 & 0.006 & 208 & 0.007 & 2.08 & 0.006 & 2.08 & 0.005 & 2.08 & 0.006 & 208 & 0.005 & 208 & 0.005 \\
\hline \multirow{3}{*}{ A3M FXX FAIRING } & Demand & 20 & & 20 & & 20 & & 1.0 & & 2.0 & & 1.0 & & 2.0 & & 20 & & 2.0 & \\
\hline & Actual & 0.7 & & 22 & & 0.8 & & 0.7 & & 1.3 & & 1.0 & & 1.0 & & 1.8 & & 2.0 & \\
\hline & godetime & 1.75 & 0.006 & 1.75 & 0.005 & 1.75 & 0.005 & 1.75 & 0.006 & 1.75 & 0.005 & 1.75 & 0.004 & 1.75 & 0.005 & 1.75 & .004 & 1.75 & 0.004 \\
\hline \multirow{3}{*}{ A320 TOPCOVER } & Demand & 8.0 & & 10.0 & & 10.0 & & 60 & & 10.0 & & 80 & & 70.0 & & 8.0 & & 10.0 & \\
\hline & Atud & 10.5 & & 9.3 & & 7.3 & & 6.8 & & 3.7 & & 6.5 & & 8.5 & & 8.0 & & 9.0 & \\
\hline & godetime & 1.75 & 006 & 1.75 & 005 & 1.75 & 05 & 1.75 & 0.006 & 1.75 & 0.005 & 1.75 & 0.004 & 1.75 & 0.005 & 1.75 & 0.004 & 175 & 0.004 \\
\hline \multirow{3}{*}{ A321 TOPCOVER } & Denand & 20 & & 20 & & 20 & & 1.0 & & 2.0 & & 20 & & 2.0 & & 20 & & $\frac{1.0}{1.0}$ & \\
\hline & Actud & 1.3 & & 22 & & 20 & & 1.2 & $n G$ & 3.0 & & 1.5 & & 1.8 & $m$ & 20 & & 2.0 & $x$ \\
\hline & Gydetin & & 006 & 75 & 5 & 1.75 & 15 & 1.75 & 06 & 75 & 0005 & 1.75 & 04 & 1.75 & 005 & 1.75 & 004 & 1.75 & 04 \\
\hline
\end{tabular}

Journal of Industrial Engineering and Management, 2013 (www.jiem.org)

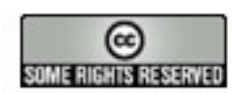

Article's contents are provided on a Attribution-Non Commercial 3.0 Creative commons license. Readers are allowed to copy, distribute and communicate article's contents, provided the author's and Journal of Industrial Engineering and Management's names are included. It must not be used for commercial purposes. To see the complete license contents, please visit http://creativecommons.org/licenses/by-nc/3.0/. 